\title{
RESEARCH
}

\section{Prevalence and incidence of hypertension from 1995 to 2005: a population-based study}

\author{
Karen Tu MD MSc, Zhongliang Chen MD MSc, Lorraine L. Lipscombe MD MSc, for the Canadian \\ Hypertension Education Program Outcomes Research Taskforce
}

$\infty \quad$ See related articles, pages I436, I44I and I458

\section{ABSTRACT}

Background: Researchers have predicted that there will be a relative increase of $24 \%$ in the prevalence of hypertension in developed countries from 2000 to 2025 . Hypertension is a leading risk factor for death, stroke, cardiovascular disease and renal disease. Thus, accurate estimates of the prevalence of hypertension in a population have important implications for public policy. We sought to assess whether the estimated increase in the prevalence of hypertension has been underestimated.

Methods: We performed a population-based cohort study using linked administrative data for adults aged 20 years and older in Ontario, Canada's most populous province with more than 12 million residents. Using a validated case-definition algorithm for hypertension, we examined trends in prevalence from 1995 to 2005 and in incidence from 1997 to 2004.

Results: The number of adults with hypertension more than doubled from 1995 to 2005 . The age- and sex-adjusted prevalence increased from $\mathbf{1 5 3 . 1}$ per 1000 adults in 1995 to 244.8 per 1000 in 2005 , which was a relative increase of $60.0 \%(p<0.001)$. The age- and sex-adjusted incidence of hypertension increased from 25.5 per 1000 adults in 1997 to 32.1 per 1000 in 2004 , which was a relative increase of $25.7 \%$ $(p<0.001)$.

Interpretation: Our findings indicate that the rise in hypertension prevalence will likely far exceed the predicted prevalence for 2025. Public health strategies to prevent and manage hypertension and its sequelae are urgently needed.

Une version française de ce résumé est disponible à l'adresse www.cmaj.ca/cgi/content/full/I78/II/I429/DCI

CMAJ 2008;178(II):1429-35 stroke and cardiovascular disease and a major cause of end-stage renal disease. Kearney and colleagues ${ }^{1}$ estimated that the prevalence of hypertension in 2000 was $26 \%$ of the adult population globally and that in 2025 the prevalence would increase by $24 \%$ in developed countries and $80 \%$ in developing countries. Results of a re- cent population-based study performed in Canada indicated that the prevalence of diabetes mellitus increased substantially from 1995 to 2005 , and that the 2005 prevalence had already exceeded the World Health Organization's projected global rate for 2030. ${ }^{2}$ This rapid rise in diabetes prevalence has been attributed to an unprecedented increase in obesity and lifestyle changes in developed countries. ${ }^{3,4}$ Obesity and sedentary lifestyles are also major risk factors for hypertension. ${ }^{5}$ Therefore, the prevalence of hypertension is also likely rising at a faster rate than predicted.

Prior population estimates for the prevalence of hypertension in Canada have been based largely on physical-measures surveys ${ }^{6}$ and patient self-report surveys. ${ }^{7}$ Although these methods are costly and time-consuming, they are not subject to bias associated with changes in physician practice patterns and diagnosis. The last physical-measures survey for hypertension in Canada was conducted between 1986 and 1992. ${ }^{6}$ Although the next physical-measures survey is expected to begin in 2008 , these surveys are limited by their inability to follow patients or assess trends over time because they are conducted only at a single point and involve a relatively small sample of patients. In Canada, self-report surveys are conducted every 2 to 3 years; however, similar to physicalmeasures surveys, they are limited in their scope and ability to follow patients over time. In addition, it is possible that participants may under-report hypertension. ${ }^{8}$ Thus, population estimates based on self-report surveys may underestimate the true prevalence of hypertension. ${ }^{9}$

Prompted by the substantial underestimation of the projection for diabetes prevalence, we sought to determine whether projections for hypertension have also been underestimated. We examined trends in the prevalence and incidence of hypertension in Canada from 1995 to 2005.

\section{Methods}

\section{Study population and data sources}

We based our study on the population of Ontario, which has more than 12 million residents and constitutes more than

From the Institute for Clinical Evaluative Sciences (Tu, Chen, Lipscombe); and the Departments of Family and Community Medicine (Tu) and Medicine (Lipscombe), University of Toronto, Toronto, Ont. 
one-third of Canada's population. In addition, Ontario has high ethnic diversity, and $85 \%$ of its residents live in urban areas. ${ }^{10}$ Ontario has a universal single-payer health care system that covers all physician and hospital services. We searched the Ontario Health Insurance Plan database for physician claims (Apr. I, I99I, to Mar. 3I, 2007) and the Canadian Institute for Health Information database for hospital admissions (Apr. I, I99I, to Mar. 3I, 2006). We linked the data from these databases together with data from the Registered Persons Database using a unique encrypted Ontario health card number that protects the identity of individuals but allows for the examination of individuals across the administrative databases. The Ontario Health Insurance Plan database records all fee-for-service billings for physician services rendered in Ontario and includes the primary diagnosis at each visit. The Canadian Institute for Health Information database records the primary diagnosis and up to 15 secondary diagnoses for all patients discharged from acute care hospitals. Studies on the validity of these administrative databases have confirmed their high degree of accuracy and comprehensiveness. ${ }^{11}$

Our study received ethics approval from the institutional review board at Sunnybrook Health Sciences Centre, Toronto, Ontario.

\section{Data synthesis}

The use of a number of different algorithms combining the data from the Ontario Health Insurance Plan and Canadian Institute for Health Information databases to identify patients with hypertension has previously been tested against data on physician-diagnosed hypertension obtained through chart ab- straction in primary care physicians' offices. For our study, we used a case-definition algorithm of 2 physician billing claims or I hospital discharge with a diagnosis of hypertension in a 2year period that had the following diagnostic codes: 40I.x, 402.x, 403.x, 404.x, or 405.x (International Classification of Disease, 9th revision) or Iro.x, III.x, II2.x, II3.x, or II5.X (International Statistical Classification of Diseases and Related Health Problems, Ioth revision). This algorithm was previously demonstrated to identify adults with hypertension with a sensitivity of $72 \%$, specificity of $95 \%$, positive predictive value of $87 \%$ and negative predictive value of $88 \%{ }^{12}$

Using this algorithm, we calculated the annual prevalence rates of hypertension among patients aged 20 years and older from fiscal years 1995 (Apr. I, I994, to Mar. 3I, 1995) to 2005 (Apr. I, 2004, to Mar. 3I, 2005). We present point prevalence and incidence rates according to the end of the fiscal periods. We chose the start date of Apr. I, I99I, to allow for sufficient time to identify prior prevalent cases of hypertension, and we chose the end date of Mar. 3I, 2007, to allow for a 2-year "look forward" period for a second physician billing claim or hospital admission because of hypertension, as dictated by our algorithm and constrained by data availability. To avoid including patients with hypertension due to pregnancy in our analysis, we excluded any hypertension-related billing claim or hospital admission that occurred within 120 days before and 90 days after an obstetric event. Once we identified patients as having hypertension and included them in our analysis, they remained part of our study population throughout the study period unless they died or moved out of the province. We classified patients as having incident hypertension based on the first database record that included a hyper-

Table 1: Prevalence of hypertension among adults 20 years and older in the province of Ontario from 1995 to 2005 , by age and sex* $\dagger$

\begin{tabular}{|c|c|c|c|c|c|c|c|c|c|}
\hline \multirow[b]{2}{*}{ Group } & \multicolumn{3}{|c|}{1995} & \multicolumn{3}{|c|}{2000} & \multicolumn{3}{|c|}{2005} \\
\hline & $\begin{array}{c}\text { No. with } \\
\text { hypertension }\end{array}$ & Population & $\begin{array}{c}\text { Rate per } \\
1000 \ddagger\end{array}$ & $\begin{array}{c}\text { No. with } \\
\text { hypertension }\end{array}$ & Population & $\begin{array}{c}\text { Rate per } \\
1000 \ddagger\end{array}$ & $\begin{array}{c}\text { No. with } \\
\text { hypertension }\end{array}$ & Population & $\begin{array}{c}\text { Rate per } \\
1000 \ddagger\end{array}$ \\
\hline \multicolumn{10}{|l|}{ Overall } \\
\hline$\geq 20 \mathrm{yr}$ & 1139478 & 7908562 & $153.1 \S$ & 1695809 & 8457720 & $202.8 \S$ & 2311042 & 9283155 & $244.8 \S$ \\
\hline $20-49 \mathrm{yr}$ & 238462 & 5107531 & 50.2 & 343696 & 5270953 & 65.8 & 460246 & 5609868 & 82.11 \\
\hline \multicolumn{10}{|l|}{ Women } \\
\hline$\geq 20 \mathrm{yr}$ & 635175 & 4066297 & $165.2^{* *}$ & 929197 & 4341264 & $216.3^{* *}$ & 1242666 & 4752682 & $257.8^{* *}+\dagger$ \\
\hline $20-49 \mathrm{yr}$ & 110584 & 2556057 & 46.5 & 160769 & 2634169 & 61.6 & 216238 & 2795880 & 77.5 \\
\hline$\geq 50 \mathrm{yr}$ & 524591 & 1510240 & 343.4 & 768428 & 1707095 & 448.1 & 1026428 & 1956802 & 528.6 \\
\hline$\geq 50 \mathrm{yr}$ & 376425 & 1290791 & 290.1 & 583685 & 1479672 & 393.5 & 824368 & 1716485 & 481.7 \\
\hline
\end{tabular}

*Significant interactions existed between age and year, and between age, sex and year ( $<0.001$ for each).

tWe used data as of Mar. 31 for each year.

†Rates are adjusted for age and sex using 2001 Canadian census data.

$\S p<0.001$ for comparison of rates between years, adjusted for age, sex, and interaction terms between age and sex.

$\Uparrow p<0.001$ for comparison of rates between age groups, adjusted for sex, year, and interaction terms between age and sex.

${ }^{* *}$ Rates are adjusted for age using 2001 Canadian census data.

$\mathrm{t} \mathrm{p}<0.001$ for comparison of rates between the sexes, adjusted for age, year, and interaction terms between age and sex. 
tension diagnosis. We present incidence rates from 1997 to 2004, allowing for a look-back period of 5 years to determine whether a patient had any prior hypertension records. In cases where there were prior records, the patient was not counted as a new hypertension case. We chose a period of 5 years because the use of shorter periods appeared to falsely elevate incidence, with some prevalent cases being erroneously considered as incident cases.

We determined rates of patients with both diagnosed hypertension and a prior diagnosis of diabetes by identifying patients who were listed in the Ontario Diabetes Database ${ }^{13}$ in the year before hypertension was diagnosed. We also examined the socioeconomic status of patients with hypertension using neighbourhood income quintiles derived from $200 \mathrm{I}$ census data by postal code, ${ }^{14,15}$ as well as residence location (rural v. urban) using Statistics Canada definitions. ${ }^{16}$

To asses potential changes in coding of administrative data for hypertension, and to determine whether more frequent visits to a physician resulted in a higher likelihood of receiving a diagnosis of hypertension, we looked at the number of visits to a primary care physician in the year before the date of diagnosis in 1997, 2000 and 2004.

\section{Statistical analysis}

We calculated annual prevalence rates by dividing the number of patients with hypertension who were alive at the end of each fiscal year by the census population count on July i of the previous year. For years when census measures were unavailable, we used estimated population measures provided by Statistics Canada. ${ }^{17}$ To calculate the annual incidence rates, we divided the annual number of new hypertension diagnoses by the annual number of patients at risk for hypertension (the total population minus the number of people with prevalent hypertension in the previous year).

To compare hypertension prevalence and incidence rates over the fiscal years, we adjusted for age and sex according to 200I Canadian census data. To compare rates between the sexes over the years, we adjusted for age using 200I census data. We used a logistic regression model to test for trends in hypertension prevalence and incidence over time, and to examine the effect of age and sex on incidence rates. We assessed the effects of fiscal year, age (in I5-year groups) and sex using a multivariable logistic regression model. We compared prevalence and incidence rates between the sexes and betweed age groups using $\chi^{2}$ analyses. We compared changes in prevalence and incidence rates between the sexes and age groups using Cochran-Mantel-Haenszel and Breslow-Day tests. We calculated the percentage change in prevalence and incidence rates between years by dividing the difference in the rate between the 2 years by the earlier rate and multiplying the result by 100 .

We used a logistic regression model to adjust for additional variables, including history of diabetes ${ }^{13}$ Charlson Comorbidity Index score (o, I or $2+),{ }^{18} 5$-year history of cardio-

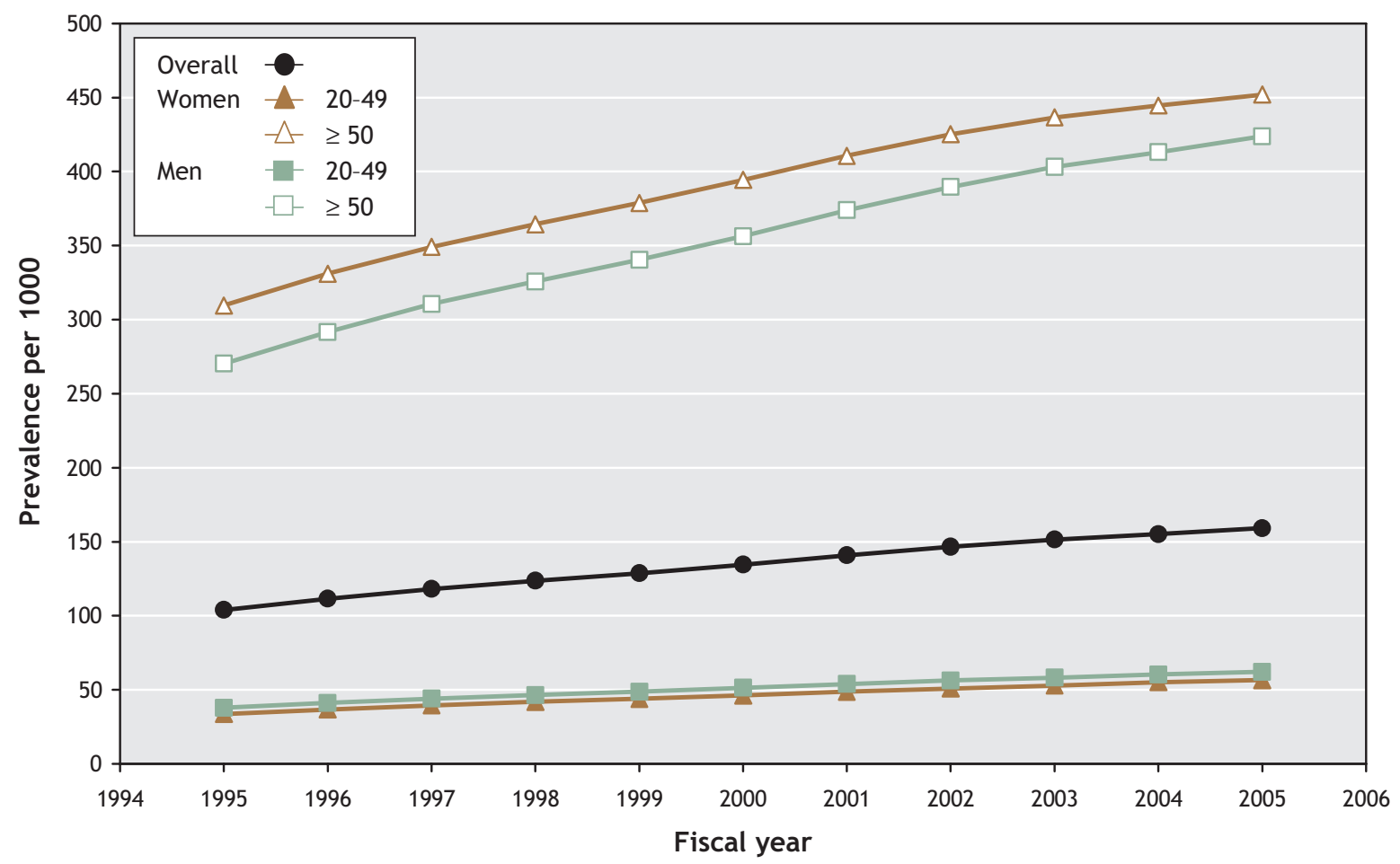

Figure 1: Prevalence of hypertension in the province of Ontario from 1995 to 2005 . We used a logistic regression model to adjust for age, sex, residence location (urban v. rural), socioeconomic status, presence of diabetes, 5-year history of cardiovascular disease, Charlson Comorbidity Index score, and interaction terms between age and sex. Yearly rates are based on prevalence as of Mar. 31 of each year. Results of the Pearson correlation test $p<0.001$. 
vascular disease,${ }^{19}$ residence location (urban v. rural) ${ }^{16}$ and socioeconomic status. ${ }^{14,15}$ We used a Pearson correlation coefficient to assess trends in annual prevalence and incidence rates, adjusted for multiple variables.

\section{Results}

The number of adults with hypertension more than doubled from 1995 to 2005 (Table I). Population increases could not account for this increase in prevalence because the adult population had a relative increase of $17.4 \%$ during this period. The age- and sex-adjusted prevalence increased from I53.I per 1000 adults in 1995 to 244.8 per 1000 in 2005 , which was a $60.0 \%$ relative increase $(p<0.001)$. Furthermore, we found that, for the period 2000-05, the prevalence rose by $20.9 \%(p<0.001)$. The average annual increase in prevalence was $4.4 \%$ (SD I.44), and the increases remained statistically significant after multivariable adjustments for age, sex, diabetes status, history of cardiovascular disease, Charlson Comorbidity Index score, socioeconomic status, and residence location (Figure I).

Our multivariable logistic regression model indicated a 2way interaction between age and year, and a 3 -way interaction between age, sex and year. The increase in populationadjusted prevalence from 1995 to 2005 was greater among men than among women: $(64.8 \%$ v. $56.0 \%$ relative increase, $p<0.001)$. Although in the younger group the number of men in whom hypertension was diagnosed was slightly higher than the number of women, the opposite was true in the group aged 50 and older (Table I and Figure I).

The age- and sex-adjusted incidence of hypertension increased from 25.5 per 1000 adults in 1997 to 32.1 per 1000 in 2004 , which was a relative increase of $25.7 \%(p<0.001)$. The incidence increased only slightly more in the younger group than in the older group (Table 2). The incidence increased rapidly from I999 to 200I, and then levelled off (Figure 2).

The percentage of people with incident hypertension who had existing diabetes increased from $10.9 \%$ in 1997 to $12.7 \%$ in 2004, which was a relative increase of $16.5 \%(p<0.00 \mathrm{I})$ (Table 3). The distribution of hypertension diagnosis was fairly even among income quintiles, and there was a slight decrease in incidence among patients in the lowest income quintiles over time (Table 3). There was also a slight decrease among patients living in rural areas (Table 3 ). The number of patients with hypertension in each of the categories of number of visits in the year before diagnosis of hypertension was similar in each year assessed (Table 3).

\section{Interpretation}

Although Kearney and colleagues ${ }^{1}$ estimated that the prevalence of hypertension would increase by $24 \%$ between 2000 and 2025 in developed countries, we found that the age- and sex-adjusted prevalence of hypertension among adults aged 20 years and older in Ontario increased by $60.0 \%$ from 1995

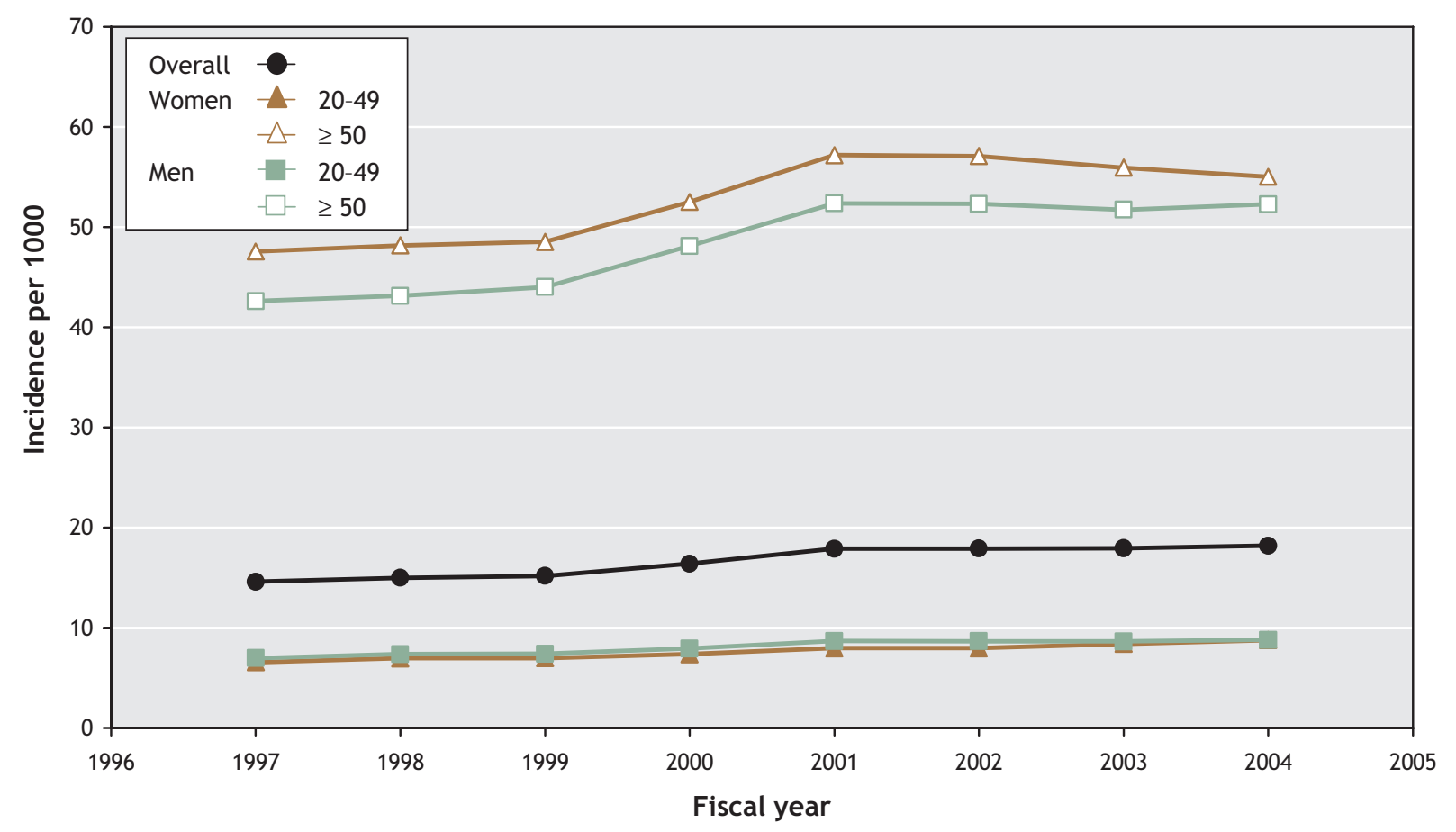

Figure 2: Incidence of hypertension in the province of Ontario from 1997 to 2004. We used a logistic regression model to adjust for age, sex, residence location (urban v. rural), socioeconomic status, presence of diabetes, 5 -year history of cardiovascular disease, Charlson Comorbidity Index score, and interaction terms between age and sex. Yearly rates are based on prevalence as of Mar. 31 of each year. Results of the Pearson correlation test were $p<0.001$ overall and for women and men aged 20-49 years, $p=0.007$ for women aged 50 years and older and $p=0.001$ for men aged 50 years and older. 
to 2005 , and by $20.9 \%$ from 2000 to 2005 . The increase in the most recent 5 -year period has almost reached what Kearney and colleagues predicted would occur over 25 years. We also found a $25.7 \%$ increase in the age- and sex-adjusted incidence of hypertension from 1997 to 2004; however, this increase in incidence alone did not appear to be sufficient to explain the overall increase in prevalence. Thus, in a separate article in this issue of $C M A J,{ }^{20}$ we examine changes in mortality among patients with hypertension over the same period.

Overall, we found that, similar to estimates of the prevalence of diabetes, the prevalence of hypertension has been underestimated. ${ }^{2}$ Although not to the same magnitude as with diabetes, the increase in prevalence of hypertension was slightly higher among younger adults than among older adults. Rising obesity rates were suggested to have contributed to the increase in diabetes, and obesity has also likely led to an increase in hypertension. ${ }^{3}$ We found that diabetes was increasingly prevalent among people with a diagnosis of hypertension. We found a more rapid increase in incidence of hypertension between 1999 and 200I. This period coincided with the start of the Canadian Hypertension Education Program. ${ }^{21,22}$ The intent of this program is to improve awareness of hypertension guidelines among health care providers, and the program may have contributed to a decrease in undiagnosed hypertension. Although the ICD diagnostic codes for hypertension changed in 2003 in the hospital admission database, a sensitivity analysis using an algorithm of 2 physician billing codes in 3 years showed a similar pattern of increase, and there have been no changes in physician billing practices or policies, such as incentives for hypertension, that could account for this increase. An increasing number of visits to the physician did not appear to increase the possibility of hypertension being diagnosed. This was similar in all 3 years assessed, which also suggests that there were no major changes in physician coding practices for hypertension during the study period.

The prevalence rates of physician-diagnosed hypertension in our study are about 3\%-4\% higher than those found in national self-report surveys during a similar period. ${ }^{23}$ They are a little lower than the estimated $5 \%$ of patients taking antihypertensive medications who do not report that they have hypertension, perhaps because they erroneously believe that they are cured if their blood pressure is under control. ${ }^{8}$ Our finding of a higher prevalence of hypertension among older women than among older men was similar to sex-related differences in the national self-report surveys; ${ }^{23}$ however, the sex-related differences in our study were slightly greater than the global predicted estimates. ${ }^{1}$

By using a validated case-definition algorithm for the administrative data, we were able to examine hypertension prevalence and incidence over a large, ethnically diverse population, and to follow our population over time. However, the validation of the algorithm that we used applied to a population aged 35 years and older. The algorithm was likely as accurate in our population, given that younger adults probably have fewer competing comorbidities than older adults.

We chose a case-definition algorithm of 2 physician billing codes or I hospital admission code in 2 years in part

Table 2: Incidence of physician-diagnosed hypertension among adults 20 years and older in the province of Ontario from 1997 to 2004 by age and sex*

\begin{tabular}{|c|c|c|c|c|c|c|}
\hline \multirow[b]{2}{*}{ Group } & \multicolumn{2}{|c|}{1997} & \multicolumn{2}{|c|}{2004} & \multicolumn{2}{|c|}{ \% change from 1997 to 2004} \\
\hline & $\begin{array}{c}\text { No. with } \\
\text { hypertension }\end{array}$ & $\begin{array}{c}\text { Rate } \\
\text { per } 1000 \dagger\end{array}$ & $\begin{array}{c}\text { No. with } \\
\text { hypertension }\end{array}$ & $\begin{array}{c}\text { Rate } \\
\text { per } 1000 \dagger\end{array}$ & $\begin{array}{l}\text { In no. } \\
\text { of cases }\end{array}$ & $\begin{array}{l}\text { In incidence } \\
\text { rate }\end{array}$ \\
\hline \multicolumn{7}{|l|}{ Overall } \\
\hline$\geq 20 \mathrm{yr}$ & 140137 & $25.5 \ddagger$ & 171338 & $32.1 \neq$ & 22.3 & $25.7 \S$ \\
\hline $20-49 \mathrm{yr}$ & 43576 & 9.4 & 60147 & 12.09 & 38.0 & $27.8^{* *}$ \\
\hline$\geq 50 \mathrm{yr}$ & 96561 & 51.4 & 111191 & 64.39 & 15.2 & $25.1^{* *}$ \\
\hline \multicolumn{7}{|l|}{ Women } \\
\hline$\geq 20 \mathrm{yr}$ & 74278 & $27.3+\dagger$ & 88427 & 34.3十抹 & 19.0 & $25.5+\dagger$ \\
\hline $20-49 \mathrm{yr}$ & 21137 & 9.1 & 29892 & 11.9 & 41.4 & 31.6 \\
\hline$\geq 50 \mathrm{yr}$ & 53141 & 54.9 & 58535 & 67.9 & 10.2 & 23.9 \\
\hline \multicolumn{7}{|l|}{ Men } \\
\hline$\geq 20 \mathrm{yr}$ & 65859 & $23.6+†$ & 82911 & 29.7†十扞 & 25.9 & 26.0干 \\
\hline $20-49 \mathrm{yr}$ & 22439 & 9.8 & 30255 & 12.1 & 34.8 & 24.3 \\
\hline$\geq 50 \mathrm{yr}$ & 43420 & 47.6 & 52656 & 60.2 & 21.3 & 26.6 \\
\hline
\end{tabular}

*We used data as of Mar. 31 for each year.

tRates are adjusted for age and sex using 2001 Canadian census data.

$\neq p<0.001$ for comparison of rates between years, adjusted for age, sex, and interaction terms between age and sex.

$\S p<0.001$ for comparison of changes in incidence rates after controlling for age and sex.

$\Uparrow p<0.001$ for comparison of 2004 incidence rates between age groups.

${ }^{* *} p<0.001$ for comparison of between-group differences by year.

††Rates are adjusted for age using 2001 Canadian census data.

$¥ \neq<0.001$ for comparison of 2004 incidence rates between the sexes. 
because of its high level of accuracy and because of constraints on data availability. Case-definition algorithms that do not use a hospital admission database may miss patients with more comorbidities because the outpatient physician billing database typically records only the primary diagnosis.

There are other limitations inherent to the use of administrative data that may have led to an underestimation of the occurrence of hypertension, which further strengthens our argument that current projections are too low. First, administrative data do not capture actual blood pressure measurements. Therefore, we rely on physician recognition of patients with hypertension. Second, our algorithm requires that patients use the health care system either as an outpatient or as an in-hospital patient. As a result, we are unable to capture undiagnosed hypertension. In addition, our algorithm has been found to miss up to $28 \%$ of cases when compared with audits of primary care physician charts, which may also be responsible for the underestimation of the true prevalence of hypertension. ${ }^{12}$ Third, our findings of a greater prevalence of hypertension among women than among men may, in part, be related to women visiting physicians more often then $\mathrm{men}^{24}$ and, therefore, having more opportunities to receive a diagnosis of hypertension. ${ }^{25}$ The extent to which this factor affects the sex-based differences in prevalence in our study cannot be measured with our administrative data. Finally, about $2 \%$ of physicians are paid salaries under alternate funding plans, and their billings do not appear in the Ontario Health Insurance Plan database. Nonetheless, it is estimated that less than $6 \%$ of the population report not having a family physician, and more than $75 \%$ of the population report visits to a primary care physician at least once a year. ${ }^{26}$ Thus, within a 2-or 3-year period, it is likely that almost all residents have at least I visit to a physician. Furthermore, in the 200r Canadian Community Health Survey, $73 \%$ of respondents reported having their blood pressure measured within the past year and $85 \%$ reported having a blood pressure measured in the 2 years before the survey. ${ }^{7}$

The prevalence of hypertension is steadily increasing, and in fewer than Io years it will likely exceed the prevalence projected for 2025. This anticipated increase, in conjunction with a comparable increase in diabetes, ${ }^{2}$ will invariably lead to dramatic rises in the incidence of cardiovascular diseases and their consequences, which has the potential to overwhelm a health care system that is modelled on underestimates. The increasing prevalence of hypertension will also have financial implications for provincial drug plans because there is increasing evidence that the majority of patients with hypertension will require 2 or more drugs to achieve blood pressure control. ${ }^{27}$ Our study highlights the need for strategies to improve the prevention of hypertension.

Table 3: Incidence of hypertension among adults aged 20 and older in 1997, 2000 and 2004, by presence of diabetes, socioeconomic status, residence location and number of primary care physician visits before incident hypertension diagnosis

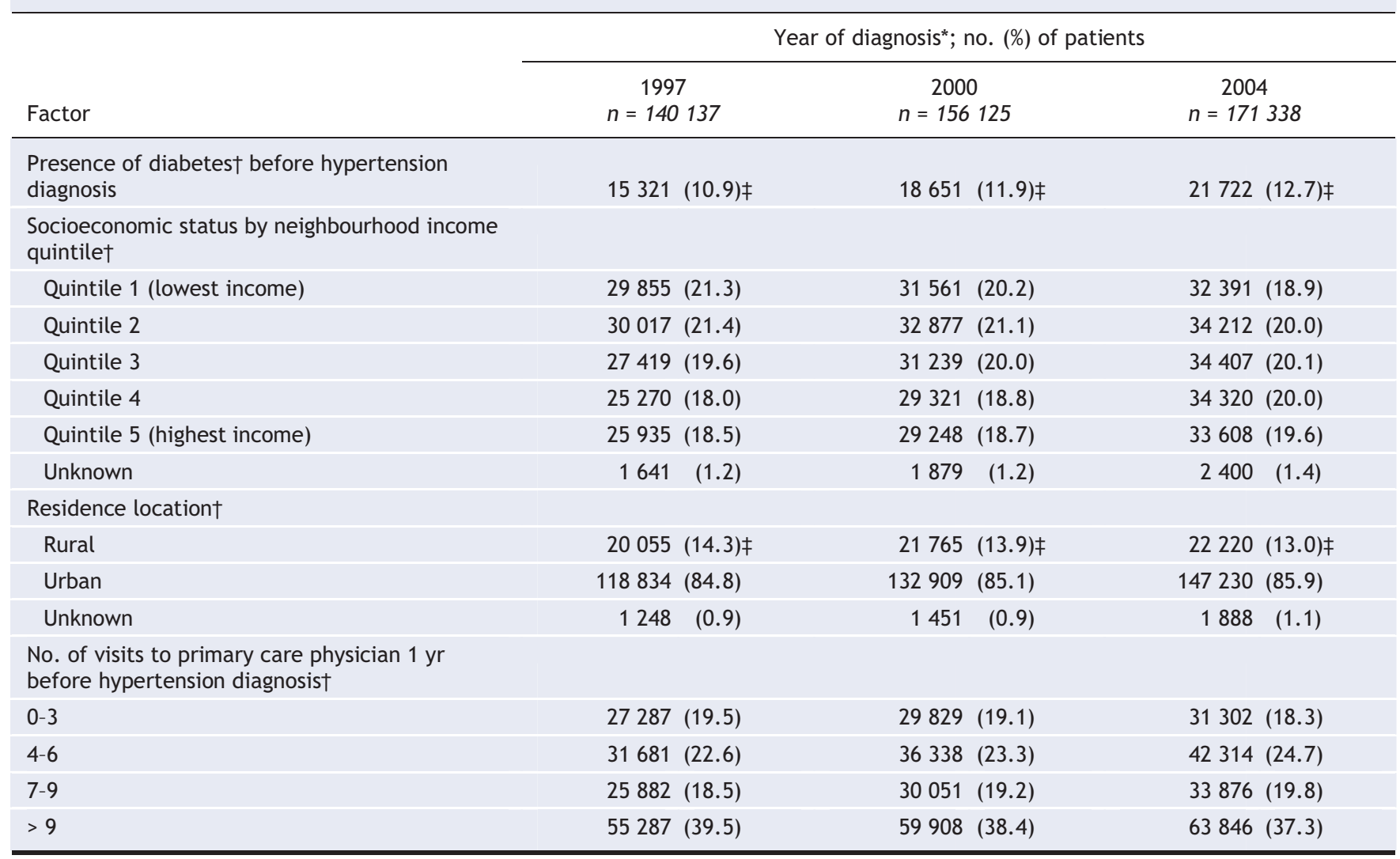

*We used data as of Mar. 31 of each year.

$t p<0.001$ for between-group differences ("unknown" category excluded) for each of the 3 years.

$\neq p<0.0001$ for difference over time. 
This article has been peer reviewed.

Competing interests: None declared.

Contributors: All authors designed the study, analyzed and interpreted the data and critically revised the manuscript for important intellectual content. Karen Tu drafted the manuscript and obtained funding for the study. Zhongliang Chen collected the data. All authors approved the final version of the manuscript submitted for publication.

Acknowledgements: We thank Dr. Finlay A. McAlister and Dr. Norman R.C. Campbell for their review of and input into this manuscript.

This research was supported by a Grant-in-Aid (no. NA 5459) from the Heart and Stroke Foundation of Ontario. The funder had no role in the design or conduct of the study; the collection, management, analysis or interpretation of the data; or the preparation, review or approval of the manuscript.

Lorraine Lipscombe is funded by a Clinician-Scientist award from the Canadian Diabetes Association and the Canadian Institutes of Health Research.

\section{REFERENCES}

I. Kearney PM, Whelton M, Reynolds K, et al. Global burden of hypertension: analysis of worldwide data. Lancet 2005;365:217-23.

2. Lipscombe LL, Hux JE. Trends in diabetes prevalence, incidence, and mortality in Ontario, Canada I995-2005: a population-based study. Lancet 2007:369:750-6.

3. Katzmarzyk PT, Mason C. Prevalence of class I, II and III obesity in Canada. CMAJ 2006; $174: 156-7$

4. Ogden CL, Carroll MD, Curtin LR, et al. Prevalence of overweight and obesity in the United States, 1999-2004. JAMA 2006;295:1549-55.

5. Manson JE, Skerrett PJ, Greenland P, et al. The escalating pandemics of obesity and sedentary lifestyle. A call to action for clinicians. Arch Intern Med 2007;164:249-58.

6. Joffres MR, Ghadirian P, Fodor JG, et al. Awareness, treatment, and control of hypertension in Canada. Am J Hypertens I997;10:1097-102.

7. Canadian Community Health Survey. Ottawa: Statistics Canada, Health Statistics Division; 200I.

8. Gentleman JF, Tomiak M. The consistency of various high blood pressure indicators based on questionnaire and physical measures data from the Canada Health Survey. Health Rep ig92;4:293-3II.

9. Onysko J, Maxwell C, Eliasziw M, et al. Large increase in hypertension diagnosis and treatment in Canada after a healthcare professional education program. $\mathrm{Hy}$ pertension 2006;48:853-60.

Io. Censuses of population, I85I-200I. Ottawa: Statistics Canada. Available: www40 .statcan.ca/lor/cstor/demo62g.htm (accessed 2007 May I8).

II. Williams JI, Young W. A summary of studies on the quality of health care administrative databases in Canada. In: Goel V, Williams JI, Anderson GM, et al., editors. Patterns of health care in Ontario. The ICES practice atlas. 2nd ed. Ottawa: Canadian Medical Association; 1996. p. 339-45.

I2. Tu K, Campbell NRC, Chen Z, et al. Accuracy of administrative databases in identifying patients with hypertension. Open Medicine 2007; I:e5-7.

13. Hux JE, Ivis F, Flintoft V, et al. Diabetes in Ontario: determination of prevalence and incidence using a validated administrative data algorithm. Diabetes Care 2002;25:512-6.

I4. Wilkins R. PCCF + Version $4 \mathrm{~J}$ user's guide. Automated geographic coding based on the Statistics Canada postal code conversion files, including postal codes through September 2006. Ottawa: Health Analysis and Measurement Group, Statistics Canada; 2007. Catalogue no 82Foo86-XDB.

I5. Mustard CA, Derksen S, Berthelot JM, et al. Assessing ecologic proxies for household income: a comparison of household and neighbourhood level income measures in the study of population health status. Health Place I999;5:157-7I.

I6. du Plessis V, Beshiri R, Bollman R, et al. Definitions of "rural." Agriculture and Rural Working Paper Series, No. 6r. Ottawa: Statistics Canada; 2002. Available: www.statcan.ca/english/research/2I-60I-MIE/2I-6oI-MIE200206I.htm (accessed 2008 Apr I8)

I7. Annual demographic statistics. Ottawa: Statistics Canada; 2005. Cat no 9I-2I3XpB Available: www.statcan.ca/bsolc/english/bnsolc?catno+9I-2I3-XpB\#formatdisp (accessed 2006 Sept 20)

I8. Deyo RA, Cherkin DC, Ciol MA. Adapting a clinical comorbidity index for use with ICD-9-CM administrative databases. J Clin Epidemiol I992;45:613-9.

I9. Lipscombe LL, Gomes T, Levesque L, et al. Thiazolidinediones and cardiovascular outcomes in older patients with diabetes. JAMA 2007;298:2634-43.

20. Tu K, Chen Z, Lipscombe LL; Canadian Hypertension Education Program Out- comes Research Taskforce. Mortality among patients with hypertension from 1995 to 2005: a population-based study. $C M A J$ 2008; I78:1436-40.

2I. Campbell NRC, Nagpal S, Drouin D. Heart and Stroke Foundation of Canada. Implementing hypertension recommendations. Can J Cardiol 200I;17:851-56.

22. Zarnke KB, Campbell NR, McAlister FA, et al. A novel process for updating recommendations for managing hypertension: rationale and methods. Can J Cardio 2000;16:1094-I02.

23. Onysko J, Maxwell C, Eliasziw M, et al. Large increase in hypertension diagnosis and treatment in Canada after a healthcare professional education program. $\mathrm{Hy}$ pertension 2006;48:853-60.

24. Jaakkimainen L, Schultz SE, Klein-Geltink JE, et al. Ambulatory physician care for adults. In: Jaakimanian L, Upshur R, Klein-Geltink JE, et al., editors. Primary care in Ontario: ICES atlas. Toronto: Institute for Clinical Evaluative Sciences; 2006. p. 53-76.

25. McAlister FA. Sex-based differences in the pharmacological treatment of hypertension: insights from health services research. JHypertens 1997;15:1527-8.

26. Chan BTB, Schultz SE. Supply and utilization of general practitioner and family physician services in Ontario. ICES investigative report. Toronto: Institute for Clinical Evaluative Sciences; 2005.

27. ALLHAT officers and coordinators for the ALLHAT Collaborative Research Group. The Antihypertensive and Lipid-Lowering Treatment to Prevent Heart Attack Trial. Major outcomes in high-risk hypertensive patients randomized to angiotensinconverting enzyme inhibitor or calcium channel blocker vs diuretic: the Antihypertensive and Lipid-Lowering Treatment to Prevent Heart Attack Trial (ALLHAT). JAMA 2002;288:298I-97.

Correspondence to: Dr. Karen Tu, Institute for Clinical Evaluative Sciences, Rm. Gro8, 2075 Bayview Ave., Toronto ON M4N 3M5; fax 4I6480-6048; karen.tu@ices.on.ca

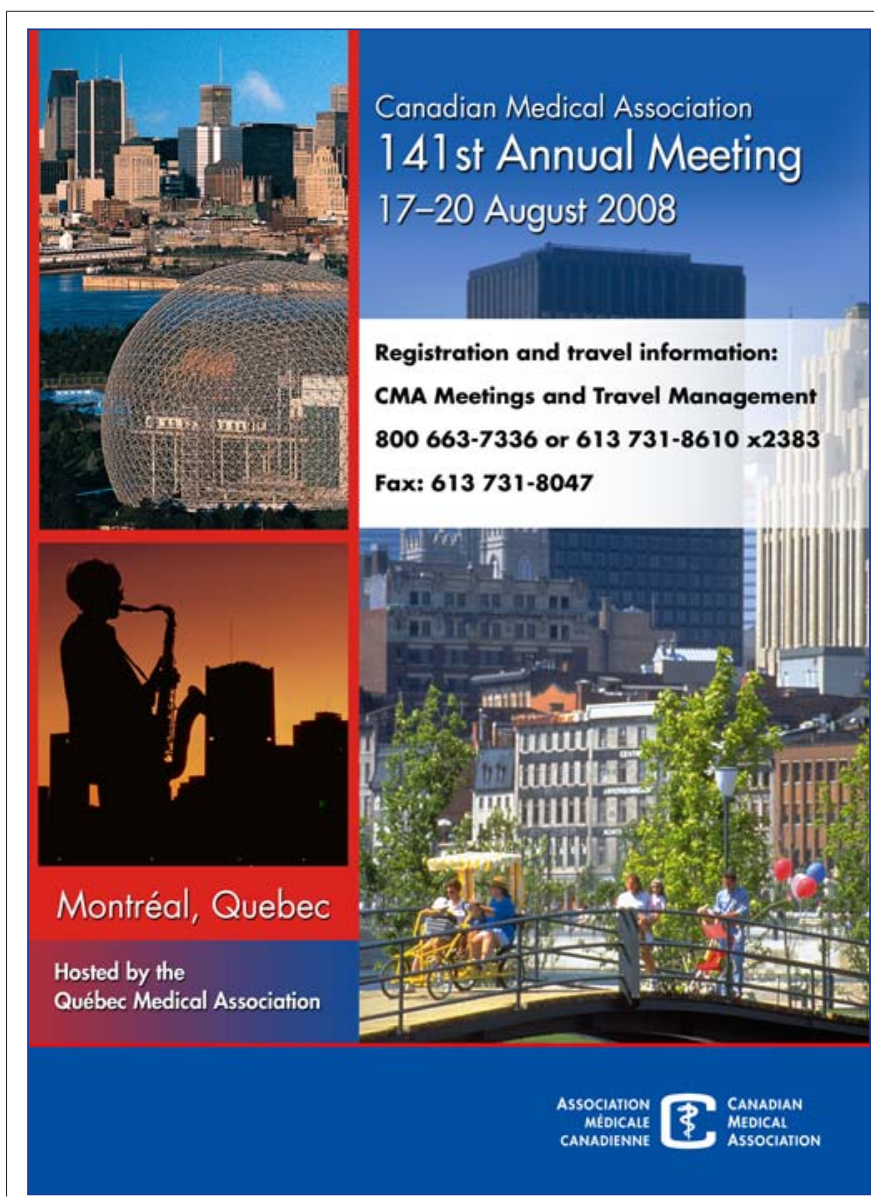

